\title{
Gene mutation analysis and genetic counseling for patients with non-syndromic hearing loss in Linyi region
}

\author{
HUAFENG LI, JIGANG QIU, JINPING ZHU and YUQIANG HUANG \\ Genetics Laboratory, Women and Children's Health Care Hospital of Linyi, Linyi, Shandong 276014, P.R. China
}

Received April 20, 2018; Accepted October 25, 2018

DOI: $10.3892 /$ etm.2018.6927

\begin{abstract}
Through gene mutation analysis of patients with non-syndromic hearing loss (NSHL) correct genetic counseling for patients with NSHL and their family members were provided. A total of 116 patients suffering from NSHL were selected, and Sanger sequencing was applied to analyze 31 mutation sites in four deafness genes [gap junction $\beta-2$ (GJB2), solute carrier family 26, member 4 (SLC26A4), GJB3 and mitochondria $12 \mathrm{~S}$ ribosomal ribonucleic acid (12SrRNA)]. Based on detection results, for the families with reproductive needs, amniotic fluid was extracted from pregnant women during proper gestational weeks to identify fetal genotypes and predict hearing state. Among 116 patients with NSHL, 51 patients carrying definite pathogenic mutation were found, including 35 patients with GJB2 mutations, 14 patients with SLC26A4 gene mutations and 2 patients with mitochondrial deoxyribonucleic acid $12 \operatorname{SrRNA}$ (mtDNA $12 \operatorname{SrRNA}$ ) mutations. No GJB3 gene mutation site was detected. In addition, prenatal diagnosis to 17 pregnant women who had given birth to babies with deafness was performed, and results suggested that genotypes of 6 fetuses were consistent with those of probands, genotypes of 8 fetuses were consistent with those of their parents, and no mutation was found in the other 3 fetuses. Gene mutation analysis of patients with NSHL can identify the etiology and provide appropriate genetic counseling and birth guiding for patients with NSHL and their family members. In addition, prenatal diagnosis to the families who plan to give birth again can avoid the natality of fetuses with hearing loss.
\end{abstract}

\section{Introduction}

Hearing loss is one of the most common birth defects in China, and the incidence rate in newborns is $1 / 1,000-3 / 1,000$ (1). Survey data from the World Health Organization (http://www.who.int)

Correspondence to: Dr Yuqiang Huang, Genetics Laboratory, Women and Children's Health Care Hospital of Linyi, 1 Qinghe South Road, Luozhuang, Linyi, Shandong 276014, P.R. China E-mail: hjs27y@163.com

Key words: genetic diagnosis, non-syndromic hearing loss, prenatal diagnosis, genetic counseling have indicated that among 360 million individuals with hearing loss, there are 32 million children. There are many factors related with hearing loss, and genetic factors, environmental factors or interactions between the two factors can cause deafness (2). It is reported that $50 \%$ of deafness is associated with genetic factors, of which $70 \%$ are classified into non-syndromic hearing loss (NSHL), and approximately $80 \%$ of NSHL are caused by autosomal recessive inheritance $(3,4)$. Previous molecular etiology studies have shown that four NSHL genes including gap junction $\beta-2$ (GJB2, OMIM: 121011), GJB3 (OMIM: 603324), solute carrier family 26, member 4 (SLC26A4, OMIM: 605646) and mitochondrial deoxyribonucleic acid 12SrRNA (mtDNA 12SrRNA, OMIM: 561000) are most common (5-9). Therefore, mutation screening of the four genes in people provides an effective method for the diagnosis of hearing loss. At the same time, prenatal diagnosis to the families with inherited hearing loss or the risk of deafness before the birth of other babies can avoid the birth of baby with hearing loss.

In this study, the above pathogenic genes in 116 patients with hearing loss were directly sequenced by polymerase chain reaction (PCR) amplified products, the causes of hearing loss in family members were identified, and the technical support of prenatal diagnosis was conducted, so as to guide families with hearing loss delivering descents with normal hearing.

\section{Patients and methods}

Subjects. Following the principle of informed consent, 116 NSHL patients who were aged from 3 months to 39 years and had genetic counseling in the Prenatal Diagnosis Center of Women and Children's Health Care Hospital of Linyi (Linyi, China) from January 2015 to June 2017 were collected. Hearing loss was $>70 \mathrm{~dB}$. Detailed medical history of deaf patients was collected, and patients with systemic diseases, dysnoesia, syndromic hearing loss, history of meningitis, otitis media or ear trauma were excluded. The study was approved by the Ethics Committee of Women and Children's Health Care Hospital of Linyi (Linyi, China). Signed written informed consents were obtained from the patients or the guardians.

\section{Methods}

DNA extraction. A total of $2 \mathrm{ml}$ venous blood from patients was collected by the ethylenediaminetetraacetic acid- $\mathrm{Na}$ (EDTA-Na) anti-coagulation tube. For pregnant women who 
would receive prenatal diagnosis, $10 \mathrm{ml}$ amniotic fluid was extracted via amniocentesis during 17-20 weeks of gestation. According to the manufacturer's instructions, DNA was extracted by the kit (Tiangen Biotech Co., Ltd., Beijing, China), a part of which was subjected to quantitative and purity tests by an ultraviolet spectrophotometer (Thermo Fisher Scientific, Inc., Waltham, MA, USA) and preserved at $-20^{\circ} \mathrm{C}$.

PCR amplification and sequencing analysis. PCR amplification reaction, PCR products purification and sequencing analysis of target DNA fragment were performed. Sequencing reaction was conducted by Shanghai Genome Pilot Institutes of Genomics and Human Health (Shanghai, China) with the use of an American ABI 373XL automated DNA sequencer (Applied Biosystems; Thermo Fisher Scientific., Inc., Waltham, MA, USA). Software including Chromas, BioEdit and SeqMan were used to make comparison and analysis of sequencing data with National Center for Biotechnology Information (NCBI) standard sequence and Cambridge Reference Sequence (CRS).

\section{Results}

In this study, 31 mutation sites in the four common genes in Chinese were detected in 116 patients with hearing loss, and 51 patients were diagnosed with definite pathogenic mutations with a positive rate of $43.96 \%$. The remaining 65 patients had no definite pathogenic mutations. The sequencing results are shown in Table I. A total of 35 patients were diagnosed with definite GJB2 mutation-induced deafness, accounting for $30.17 \%(35 / 116)$ of all subjects. Among them, homozygous mutations were identified in 21 patients, and compound heterozygous mutations were found in 14 patients. Definite GJB2 gene mutation-induced hearing loss was identified in 14 patients, of which the prevalence rate was $12.07 \%$ among all subjects. Among them, homozygous mutations were identified in 7 patients, and compound heterozygous mutations were found in 7 patients. A total of $2(2 / 116,1.72 \%)$ patients were found carrying mtDNA $12 \operatorname{SrRNA} 1555 \mathrm{~A}>\mathrm{G}$ mutations, and they had administration history of aminoglycoside. No GJB3 gene mutation site was detected. All in all, a total of six GJB2 mutation sites (Fig. 1) and five SLC26A4 mutation sites were identified (Fig. 2).

Among 116 patients with hearing loss, 17 were identified with mutations in the GJB2 or SLC26A4 gene. Subsequently, their parents received tests of genes associated with hearing loss, which indicated that they were carriers. Sequencing results are shown in Table II. All of the 17 families had the need for further fertility. During their next pregnancy, prenatal diagnosis was performed. The results suggested that the genotypes of 6 fetuses were consistent with those of the probands, so the 6 families decided to terminate the pregnancy. No mutation was found in 3 fetuses. The genotypes of the other 5 children were consistent with those of their parents. Follow-up results showed that their fetuses had normal hearing after birth.

\section{Discussion}

Due to genetic heterogeneity and phenotypic diversity shown in patients with hearing loss, providing proper genetic counseling for patients is still a great challenge clinically. Up to
Table I. Results of genetic test of 51 patients with hearing loss.

\begin{tabular}{|c|c|c|c|c|}
\hline Gene & Mutation site & $\begin{array}{l}\text { No. of } \\
\text { patients } \\
\text { (case) }\end{array}$ & $\begin{array}{c}\text { Total } \\
\text { no. } \\
\text { (case) }\end{array}$ & $\begin{array}{l}\text { Proportion } \\
\quad(\%)\end{array}$ \\
\hline \multirow[t]{11}{*}{ GJB2 } & 235delC/235delC & 18 & 35 & 30.17 \\
\hline & 235delC/299-300delAT & 7 & & \\
\hline & 235delC/176-191del16bp & 1 & & \\
\hline & 235delC/511-512insAACG & 1 & & \\
\hline & 235delC/30-35insG & 1 & & \\
\hline & 299-300delAT/299-300delAT & 2 & & \\
\hline & $109 \mathrm{G}>\mathrm{A} / 109 \mathrm{G}>\mathrm{A}$ & 1 & & \\
\hline & 109G >A/176-191del16bp & 1 & & \\
\hline & 109G>A/299-300delAT & 2 & & \\
\hline & 176-191del16bp/ & & & \\
\hline & 511-512insAACG & 1 & & \\
\hline \multirow[t]{5}{*}{ SLC26A4 } & IVS7-2A $>G / I V S 7-2 A>G$ & 7 & 14 & 12.07 \\
\hline & IVS7-2A>G/1226G>A & 2 & & \\
\hline & IVS7-2A $>G / 2168 \mathrm{~A}>\mathrm{G}$ & 3 & & \\
\hline & IVS7-2A $>G / 1614+1 G>A$ & 1 & & \\
\hline & IVS7-2A > G/2009T>C & 1 & & \\
\hline $12 S r R N A$ & $1555 \mathrm{~A}>\mathrm{G}$ & 2 & 2 & 1.72 \\
\hline Total & & & 51 & 43.96 \\
\hline
\end{tabular}

GJB2, gap junction $\beta-2 ; S L C 26 A 4$, solute carrier family 26, member 4; $12 \operatorname{Sr} R N A, 12 \mathrm{~S}$ ribosomal ribonucleic acid.

now, hundreds of genes causing hereditary hearing loss have been identified. Most of NSHL are induced by mutations in the four genes including GJB2, SLC26A4, mtDNA 12SrRNA and GJB3 (5-9). The findings provide theoretic basis for the implementing of prenatal diagnosis of deafness genes. In this study, Sanger sequencing was employed to analyze the 31 mutation sites in these four genes in 116 NSHL patients.

In this study, 35 (30.17\%) patients carrying GJB2 mutations were detected, among which, 21 patients had GJB2 genetic homozygous mutations, and 14 had GJB2 compound heterozygous mutations. GJB2 $235 \mathrm{delC}$ had the highest percentage, followed by 299_300delAT. Epidemiological studies of GJB2 mutations in deaf patients in different countries have revealed that $46 \%$ of Hungarian patients with NSHL were caused by GJB2 mutations, $24.3 \%$ of patients with NSHL among Americans were induced by GJB2 mutations, and $12.2-33 \%$ of patients with NSHL among Chinese were due to GJB2 mutations (10). In this study, it was found that $30.17 \%$ of patients with NSHL were caused by GJB2 mutations, which suggested that the $G J B 2$ gene mutation plays an important role in hereditary NSHL. The types of GJB2 mutation are different in different regions or races. Studies of Yu et al (11) and Dai et al (12) have suggested that the mutation types of the most common GJB2 in the Chinese people are 235delC, 299_300delAT and 176_191del16bp. In this study, 235delC accounted for the highest percentage, followed by 299_300delAT and 109G>A. A study by Zhang et al (13) found that the mutation types of GJB2 in patients with HSHL are consistent in Linyi. 
A

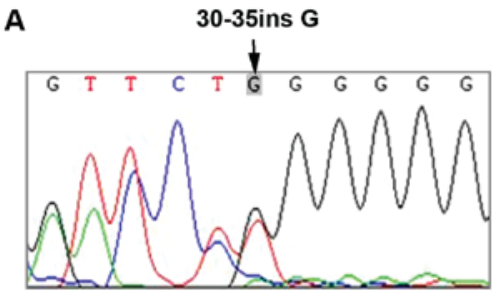

c

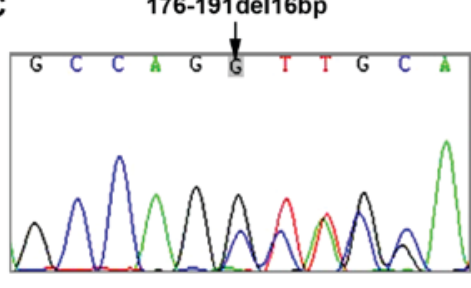

E

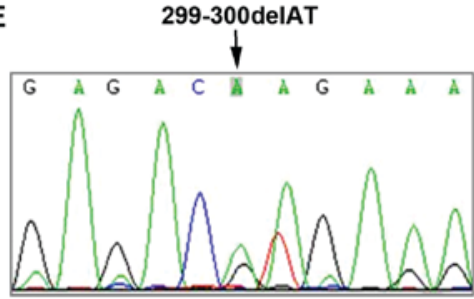

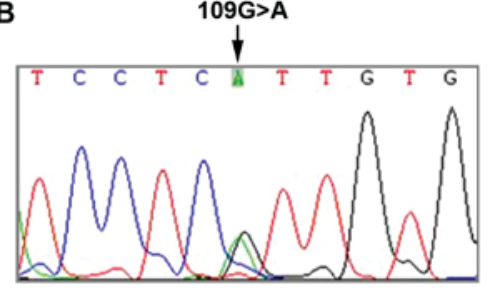

D

235delC

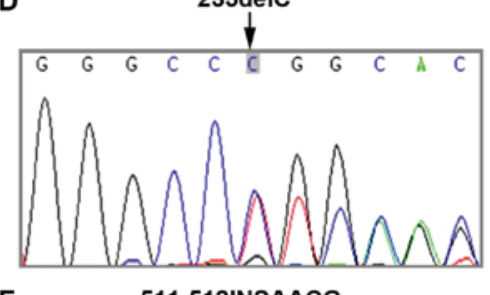

$\mathbf{F}$

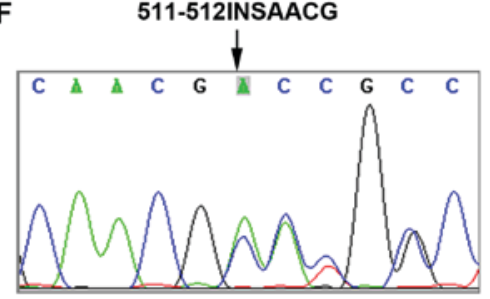

Figure 1. GJB2 mutation sites and types. (A) 30-35ins G, (B) 109G>A, (C) 176-191del16bp, (D) 235delC, (E) 299-300delAT and (F) 511-512insAACG heterozygous mutations. Nucleotide mutation sites are indicated by arrows. GJB2, gap junction $\beta-2$.

A

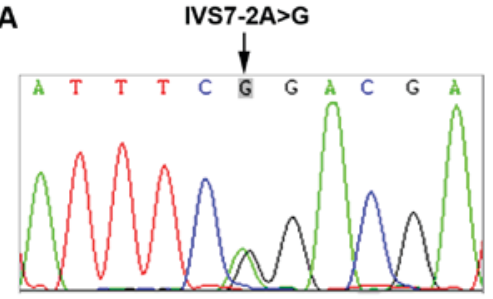

C

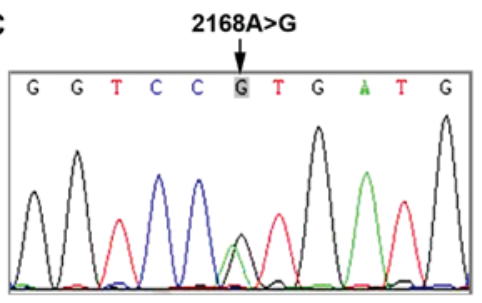

B $1226 \mathrm{G}>\mathrm{A}$

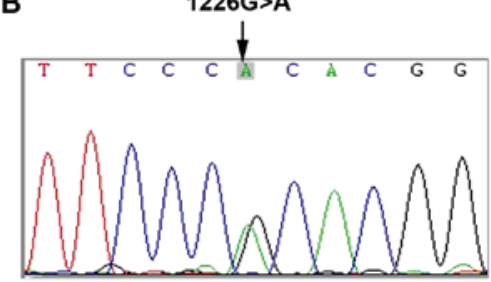

D $1614+1 G>A$

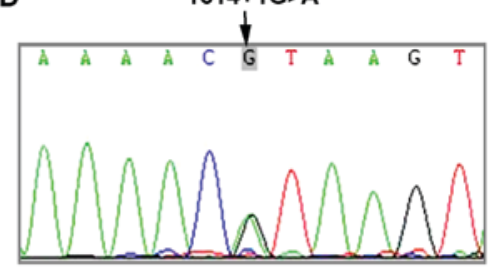

E

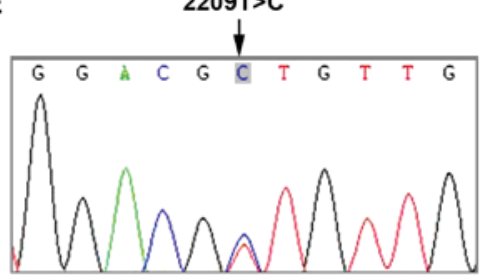

Figure 2. SLC26A4 mutation sites and types. (A) IVS7-2A $>$ G, (B) 1226G >A, (C) 2168A $>\mathrm{G}$, (D) 1614+1G $>\mathrm{A}$ and (E) 2009T>C heterozygous mutations. Nucleotide mutation sites are indicated by arrows. SLC26A4, solute carrier family 26, member 4.

SLC26A4 gene mutations will cause large vestibular aqueduct syndrome, of which the mutation frequency ranks second in patients with NSHL, next to GJB2 gene (14). Chai et al (15) reported that the incidence rate of $S L C 26 A 4$ gene mutations in Chinese patients with NSHL is $11.2 \%$, and in this study it was $12.07 \%$. A study on patients with NSHL in China by Yuan et al (16) showed that the most common SLC26A4 mutations in China are IVS7-2A>G, 2168A $>\mathrm{G}$ and $1174 \mathrm{~A}>\mathrm{T}$. In this study, it was found that the most common mutation in SLC26A4 was IVS7-2A $>\mathrm{G}$, which is consistent with the findings of Yuan et al (16).

In this study, 2 patients were found carrying the mtDNA 12SrRNA $1555 \mathrm{~A}>\mathrm{G}$ mutations, which accounted for $1.72 \%$. Carrying mtDNA $12 \operatorname{SrRNA}$ mutations can lead to the 
Table II. Sequencing results of the family members of the 17 hearing loss patients with prenatal diagnosis.

\begin{tabular}{|c|c|c|c|c|c|}
\hline $\begin{array}{l}\text { No. of } \\
\text { case }\end{array}$ & Proband & Father & Mother & Fetus & $\begin{array}{l}\text { Follow-up } \\
\text { results }\end{array}$ \\
\hline $1^{\mathrm{b}}$ & IVS7-2A $>\mathrm{G} / 2009 \mathrm{~T}>\mathrm{C}$ & $2009 \mathrm{~T}>\mathrm{C} / \mathrm{WT}$ & IVS7-2A>G/WT & WT/WT & Normal hearing \\
\hline $2^{\mathrm{a}}$ & 299-300delAT/299-300delAT & 299-300delAT/WT & 299-300delAT/WT & 299-300delAT/299-300delAT & Induced labor \\
\hline $3^{\mathrm{a}}$ & 235delC/235delC & 235delC/WT & 235delC/WT & 235delC/WT & Normal hearing \\
\hline $4^{\mathrm{a}}$ & 235delC/235delC & 235delC/WT & 235delC/WT & 235delC/235delC & Induced labor \\
\hline $5^{\mathrm{a}}$ & 235delC/235delC & 235delC/WT & 235delC/WT & 235delC/235delC & Induced labor \\
\hline $6^{\mathrm{a}}$ & 235delC/235delC & 235delC/WT & 235delC/WT & WT/WT & Normal hearing \\
\hline $7^{\mathrm{a}}$ & $35 \mathrm{insG} / 235 \mathrm{delC}$ & 235delC/WT & 35insG/WT & 235delC/WT & Normal hearing \\
\hline $8^{\mathrm{a}}$ & 235delC/235delC & 235delC/WT & 235delC/WT & 235delC/WT & Normal hearing \\
\hline $9^{a}$ & $235 \mathrm{delC} / 235 \mathrm{delC}$ & 235delC/WT & 235delC/WT & 235delC/WT & Normal hearing \\
\hline $10^{\mathrm{b}}$ & IVS7-2A $>$ G/IVS7-2A $>G$ & IVS7-2A $>$ G/WT & IVS7-2A>G/WT & IVS7-2A $>$ G/IVS7-2A $>G$ & Induced labor \\
\hline $11^{\mathrm{b}}$ & IVS7-2A>G/1226G >A & IVS7-2A >G/WT & $1226 \mathrm{G}>\mathrm{A} / \mathrm{WT}$ & $1226 \mathrm{G}>\mathrm{A} / \mathrm{WT}$ & Normal hearing \\
\hline $12^{\mathrm{a}}$ & 235delC/511-512insAACG & 511-512insAACG/WT & 235delC/WT & 235delC/WT & Induced labor \\
\hline $13^{\mathrm{a}}$ & 235delC/235delC & $235 \mathrm{delC} / \mathrm{WT}$ & 235delC/WT & 235delC/WT & Induced labor \\
\hline $14^{\mathrm{a}}$ & 235delC/235delC & 235delC/WT & 235delC/WT & WT/WT & Normal hearing \\
\hline $15^{\mathrm{b}}$ & IVS7-2A $>$ G/IVS7-2A $>G$ & IVS7-2A>G/WT & IVS7-2A>G/WT & IVS7-2A $>$ G/IVS7-2A $>G$ & Induced labor \\
\hline $16^{\mathrm{a}}$ & 235delC/235delC & 235delC/WT & 235delC/WT & 235delC/235delC & Induced labor \\
\hline $17^{\mathrm{b}}$ & IVS7-2A $>$ G/IVS7-2A $>G$ & IVS7-2A>G/WT & IVS7-2A>G/WT & IVS7-2A>G/WT & Normal hearing \\
\hline
\end{tabular}

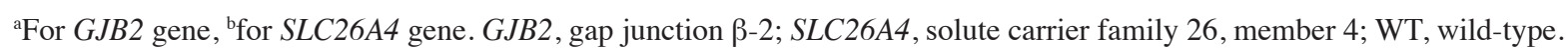

occurrence of aminoglycoside drug-induced deafness (17). However, the proportion of patients with drug-induced deafness is small due to the strict application requirements of aminoglycosides in clinical practice. In this study, no carrier of the definite GJB3 mutation site was discovered, which might be resulted from the small sample size. Therefore, further verification is needed.

In this study, prenatal diagnosis to 17 families with hearing loss induced by definite pathogenic mutation suggested that all their parents were carriers. Moreover, genetic analysis and genetic counseling showed that genotypes of 6 fetuses were in line with those of probands, so the 6 families decided to terminate the pregnancy. No mutation was found in 3 fetuses, and the genotypes of the other 8 fetuses were consistent with their parents. Follow-up results showed that the 11 fetuses had normal hearing after birth.

The deafness genes including GJB2, GJB3 and SLC26A4 are mainly autosomal recessively inherited, while $12 \operatorname{SrRNA}$ is maternally inherited $(18,19)$. Detection of deafness couples and parents of patients with mutations in GJB2, SLC26A4 and $12 S r R N A$ genes were performed to determine the genotypes and estimate recurrence risk on the basis of genotypes. If the pathogenic genes carried by parents are located on different genes, their descendants are at a lower risk of illness and do not need prenatal diagnosis. If the parents are carriers of the same gene mutation (GJB2 or SLC26A4), their offspring have a $25 \%$ risk of deafness. Prenatal diagnosis is recommended for a further birth. If mothers carry $12 \operatorname{SrRNA}$ mutations, for their siblings, mother as well as offspring, the administration of aminoglycosides should be banned for life, which can effectively prevent the occurrence of deafness.
To sum up, application of gene sequencing is very useful to the genetic testing for patients with NSHL. In addition, this method is simple in operation and can be applied in clinical practice, providing accurate genetic counseling clinically.

\section{Acknowledgements}

Not applicable.

\section{Funding}

No funding was received.

\section{Availability of data and materials}

The datasets used and/or analyzed during the present study are available from the corresponding author on reasonable request.

\section{Authors' contributions}

HL drafted the manuscript. HL and JQ were mainly devoted to DNA extraction. JZ and YH were responsible for PCR. All authors read and approved the final manuscript.

\section{Ethics approval and consent to participate}

The study was approved by the Ethics Committee of Women and Children's Health Care Hospital of Linyi (Linyi, China). Signed written informed consents were obtained from the patients or the guardians. 


\section{Patient consent for publication}

Not applicable.

\section{Competing interests}

The authors declare that they have no competing interests.

\section{References}

1. Morton CC and Nance WE: Newborn hearing screening - a silent revolution. N Engl J Med 354: 2151-2164, 2006.

2. Shearer AE and Smith RJ: Genetics: Advances in genetic testing for deafness. Curr Opin Pediatr 24: 679-686, 2012.

3. Bozdoğan ST, Kuran G, Yüregir OO, Aslan H, Haytoğlu S, Ayaz A and Arikan OK: The prevalence of gap junction protein beta 2 (GJB2) mutations in non syndromic sensorineural hearing loss in Çukurova region. J Int Adv Otol 11: 118-121, 2015.

4. Hoefsloot LH, Feenstra I, Kunst HP and Kremer H: Genotype phenotype correlations for hearing impairment: Approaches to management. Clin Genet 85: 514-523, 2014.

5. Fang Y, Gu M, Wang C, Suo F, Wang G and Xia Y: GJB2 as well as SLC26A4 gene mutations are prominent causes for congenital deafness. Cell Biochem Biophys 73: 41-44, 2015.

6. Dai P, Stewart AK, Chebib F, Hsu A, Rozenfeld J, Huang D, Kang D, Lip V, Fang H, Shao H, et al: Distinct and novel SLC26A4/Pendrin mutations in Chinese and U.S. patients with nonsyndromic hearing loss. Physiol Genomics 38: 281-290, 2009.

7. Li Z, Li R, Chen J, Liao Z, Zhu Y, Qian Y, Xiong S, Heman-Ackah S, Wu J, Choo DI, et al: Mutational analysis of the mitochondrial $12 S r R N A$ gene in Chinese pediatric subjects with aminoglycoside-induced and non-syndromic hearing loss. Hum Genet 117: 9-15, 2005.

8. Xia JH, Liu CY, Tang BS, Pan Q, Huang L, Dai HP, Zhang BR, Xie W, Hu DX, Zheng D, et al: Mutations in the gene encoding gap junction protein beta-3 associated with autosomal dominant hearing impairment. Nat Genet 20: 370-373, 1998.

9. Ma D, Zhang J, Luo C, Lin Y, Ji X, Hu P and Xu Z: Genetic counseling for patients with nonsyndromic hearing impairment directed by gene analysis. Mol Med Rep 13: 1967-1974, 2016.

10. Dai ZY, Sun BC, Huang SS, Yuan YY, Zhu YH, Su Y and Dai P. Correlation analysis of phenotype and genotype of GJB2 in patients with non-syndromic hearing loss in China. Gene 570 272-276, 2015.
11. Yu F, Han DY, Dai P, Kang DY, Zhang X, Liu X, Zhu QW, Yuan YY, Sun Q, Xue DD, et al: Mutation of GJB2 gene in nonsyndromic hearing impairment patients: Analysis of 1190 cases. Zhonghua Yi Xue Za Zhi 87: 2814-2819, 2007 (In Chinese).

12. Dai P, Yu F, Han B, Liu X, Wang G, Li Q, Yuan Y, Liu X, Huang D, Kang D, et al: GJB2 mutation spectrum in 2,063 Chinese patients with nonsyndromic hearing impairment. J Transl Med 7: 26, 2009.

13. Zhang F, Xiao Y, Xu L, Zhang X, Zhang G, Li J, Lv H, Bai X and Wang H: Mutation analysis of the common deafness genes in patients with nonsyndromic hearing loss in Linyi by SNP scan assay. Biomed Res Int 2016: 1302914, 2016.

14. Du W, Guo Y, Wang C, Wang Y and Liu X: A systematic review and meta-analysis of common mutations of SLC26A4 gene in Asian populations. Int J Pediatr Otorhinolaryngol 77: 1670-1676, 2013.

15. Chai Y, Huang Z, Tao Z, Li X, Li L, Li Y, Wu H and Yang T: Molecular etiology of hearing impairment associated with nonsyndromic enlarged vestibular aqueduct in East China. Am J Med Genet A 161A: 2226-2233, 2013.

16. Yuan Y, Guo W, Tang J, Zhang G, Wang G, Han M, Zhang X, Yang S, He DZZ and Dai P: Molecular epidemiology and functional assessment of novel allelic variants of SLC26A4 in non-syndromic hearing loss patients with enlarged vestibular aqueduct in China. PLoS One 7: e49984, 2012.

17. O'Sullivan M, Rutland P, Lucas D, Ashton E, Hendricks S, Rahman S and Bitner-Glindzicz M: Mitochondrial m.1584A 12S m62A rRNA methylation in families with $\mathrm{m} .1555 \mathrm{~A}>\mathrm{G}$ associated hearing loss. Hum Mol Genet 24: 1036-1044, 2015.

18. Yao GD, Li SX, Chen DL, Feng HQ, Zhao SB, Liu YJ, Guo LL, Yang ZM, Zhang XF, Sun CX, et al: Combination of hearing screening and genetic screening for deafness-susceptibility genes in newborns. Exp Ther Med 7: 218-222, 2014.

19. Kim MA, Kim YR, Sagong B, Cho HJ, Bae JW, Kim J, Lee J, Park HJ, Choi JY, Lee KY, et al: Genetic analysis of genes related to tight junction function in the Korean population with non-syndromic hearing loss. PLoS One 9: e95646, 2014.

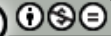

This work is licensed under a Creative Commons Attribution-NonCommercial-NoDerivatives 4.0 International (CC BY-NC-ND 4.0) License. 